\title{
Comparative study of peri-operative outcome following laparotomy versus laparoscopic technique of abdominal hysterectomy for benign gynaecological lesions
}

\author{
Satyajit P. Gavhane, Dhruval K. Bhavsar, Vidyadhar B. Bangal*, \\ Swati D. Gagare, Amey R. Kodlikeri
}

Department of Obstetrics and Gynecology, Rural Medical College, Pravara Institute of Medical Sciences, Loni, Maharashtra, India

Received: 20 March 2018

Accepted: 21 April 2018

*Correspondence:

Dr. Vidyadhar B. Bangal,

E-mail: vbb217@rediffmail.com

Copyright: $(\odot$ the author(s), publisher and licensee Medip Academy. This is an open-access article distributed under the terms of the Creative Commons Attribution Non-Commercial License, which permits unrestricted non-commercial use, distribution, and reproduction in any medium, provided the original work is properly cited.

\section{ABSTRACT}

Background: Laparoscopic technique of hysterectomy is becoming increasingly popular in developing and developed world. Laparoscopic hysterectomy is a minimal access procedure that allows patients to recover faster. The study was undertaken to assess the impact of two abdominal techniques (laparoscopic and conventional laparotomy) on various variables like operative time, hospital stay, complications and convalescence period.

Methods: An observational longitudinal study was carried out at tertiary care centre. Two hundred and ten women, as per inclusion and exclusion criteria, who had undergone abdominal hysterectomy for benign uterine pathology, either by laparotomy (Group A) or by laparoscopic technique (Group B) during study period were included. Data was analyzed and compared by using different variables between two methods of hysterectomy, using percentages and Chi square test for normal distribution. $\mathrm{P}$ value less than 0.05 was considered significant.

Results: The mean duration of surgery was 100 minutes in group A and 175 minutes in Group B. There were two cases $(1.90 \%)$ of minor injury to urinary bladder in Group A and one case $(0.95 \%)$ of thermal injury to urinary bladder in Group B. The mean blood loss was around $240 \mathrm{ml}$ and $70 \mathrm{ml}$ in Group A and B respectively. The need for postoperative analgesia was observed in $100 \%$ cases from Group A and 38.09\% from group B. The average duration required for out of bed ambulation was 25 hours and 14 hours in Group A and B respectively. The mean hospital stay in group A and B was 7.5 days and 3.5 days respectively.

Conclusions: Following laparoscopic hysterectomy, women had less morbidity, less need for post-operative pain relief, had early ambulation, short hospital stay and early resumption of routine activities at home as compared to women who had undergone abdominal hysterectomy by conventional method.

Keywords: Abdominal hysterectomy, Complications of hysterectomy, Laparoscopic hysterectomy, Surgical site infections

\section{INTRODUCTION}

Hysterectomy is one of the most frequently performed operations in Gynecology. Traditionally the uterus has been removed by an abdominal or vaginal route. In spite of the lower complication rate in vaginal hysterectomies, abdominal hysterectomy has been the main method of hysterectomy in the developed countries. ${ }^{1-5}$ Laparoscopic hysterectomy (LH) is an innovation in the Gynaecologist's armamentarium. It is a minimal access procedure that allows patients to recover faster. Approximately 6,00,000 hysterectomies are performed annually in the United States, of which $70 \%$ are performed by the abdominal route. ${ }^{6,7}$ In some countries 
the rate is as high as $95 \% .^{8}$ However, the laparoscopic approach is clearly superior to laparotomy. ${ }^{7,8}$ The advantages of laparoscopic hysterectomy over abdominal hysterectomy have been reported to be less postoperative pain, shorter hospital stays and more rapid return to normal activities and work. ${ }^{9,10}$ The study was undertaken to assess the impact of two abdominal techniques (laparoscopic and conventional laparotomy) on various variables like operative time, hospital stay, complications and convalescence.

\section{METHODS}

An observational longitudinal study was carried out at tertiary care centre over a period of 22 months. Two hundred and ten women, as per inclusion and exclusion criteria, who had undergone abdominal hysterectomy for benign uterine pathology, either by laparotomy or by laparoscopic technique during study period were included. Cases were distributed as follows.

Group A: Hysterectomy performed through laparotomy and

Group B: Hysterectomy performed by laparoscopy. Hysterectomy operation by either of the techniques was performed under general anaesthesia by same team of surgeons. Patients operated by either of the techniques received a single dose of prophylactic antibiotic in the form of Inj.Cefotaxime 1 gram and Inj.Metronidazole $500 \mathrm{mgs}$ at $8 \mathrm{am}$ on the day of surgery. Same antibiotics were continued for seven days.

In addition to the antibiotics, all cases received antiinflammatory drugs in the form of combination of diclofenac sodium-50 mg twice daily and tablet vitaminC 500mg once daily from second to seventh day after hysterectomy operation.

Data related to age, indication for hysterectomy, technique of operation, duration of surgery and anaesthesia, intra-operative complications, need for postoperative nursing care, need for post-operative pain relief, duration of parenteral fluid therapy, timing of ambulation, infective morbidity, surgical site infections, hospital stay, wound related late complications and period of post-operative rest taken in hysterectomy by conventional laparotomy and by laparoscopy, was collected.

Data was analyzed and compared by using different variables between two methods of hysterectomy, using percentages and chi square test for normal distribution. $\mathrm{P}$ value less than 0.05 was considered significant.

\section{RESULTS}

The mean duration of surgery was 100 minutes in group A and 175 minutes in Group B (Table 1).
Table 1: Distribution of cases as per duration of surgery.

\begin{tabular}{|lll|}
\hline $\begin{array}{l}\text { Duration of } \\
\text { surgery (hrs) }\end{array}$ & $\begin{array}{l}\text { TAH (Group } \\
\text { A) }(\mathbf{n = 1 0 5})\end{array}$ & $\begin{array}{l}\text { TLH } \\
(\text { Group B) } \\
(\mathbf{n = 1 0 5})\end{array}$ \\
\hline$<1$ & $03(02.80)$ & $00(00.00)$ \\
\hline $1-1.5$ & $17(16.10)$ & $04(03.80)$ \\
\hline $1.5-2$ & $46(43.80)$ & $21(20.00)$ \\
\hline $2-2.5$ & $24(22.80)$ & $37(35.20)$ \\
\hline $2.5-3$ & $11(10.40)$ & $24(22.80)$ \\
\hline$>3$ & $04(03.80)$ & $19(18.09)$ \\
\hline Mean \pm SD & $1.78 \pm 0.26$ & $1.93 \pm 0.87$ \\
\hline
\end{tabular}

Value of $\chi^{2}=37.758, p=0.0001$, significant.

There were two cases $(1.90 \%)$ of minor injury to urinary bladder in Group A and one case $(0.95 \%)$ of thermal injury to urinary bladder in Group B (Table 2).

Table 2: Distribution of cases as per intra operative complications.

\begin{tabular}{|lll|}
\hline $\begin{array}{l}\text { Intra operative } \\
\text { complication }\end{array}$ & $\begin{array}{l}\text { TAH (Group } \\
\mathbf{n}=\mathbf{1 0 5}(\%)\end{array}$ & $\begin{array}{l}\text { TLH } \\
\text { (Group B }) \\
\mathrm{n=105}(\%)\end{array}$ \\
\hline Injury to bladder & $2(01.90)$ & $0(00.00)$ \\
\hline Injury to bowel & $0(00.00)$ & $0(00.00)$ \\
\hline Primary hemorrhage & $0(00.00)$ & $0(00.00)$ \\
\hline $\begin{array}{l}\text { Thermal injury to } \\
\text { viscera }\end{array}$ & $0(00.00)$ & $1(00.95)$ \\
\hline $\begin{array}{l}\text { Need for conversion } \\
\text { to laparotomy }\end{array}$ & $0(00.00)$ & $0(00.00)$ \\
\hline
\end{tabular}

The intra-operative blood loss in maximum number of cases (40.00\%) in Group A, was in between 200-300 ml, whereas; in maximum number of cases (66.33\%) in Group B, it was less than $50 \mathrm{ml}$. The mean blood loss was around $240 \mathrm{ml}$ and $70 \mathrm{ml}$ in Group A and B respectively (Table 3).

Table 3: Distribution of cases as per estimated intraoperative blood loss.

\begin{tabular}{|lll|}
\hline $\begin{array}{l}\text { Intra-operative } \\
\text { Blood loss }(\mathrm{ml})\end{array}$ & $\begin{array}{l}\text { TAH (Group } \\
\text { A) } n=105(\%)\end{array}$ & $\begin{array}{l}\text { TLH } \\
\text { (Group B) } \\
\text { n=105 }(\%)\end{array}$ \\
\hline$<50 \mathrm{ml}$ & $08(07.60 \%)$ & $70(66.60 \%)$ \\
\hline $50-100 \mathrm{ml}$ & $07(06.60 \%)$ & $31(29.50 \%)$ \\
\hline $100-200 \mathrm{ml}$ & $38(36.10 \%)$ & $04(03.80 \%)$ \\
\hline $200-300 \mathrm{ml}$ & $42(40.00 \%)$ & $00(00.00 \%)$ \\
\hline $300-400 \mathrm{ml}$ & $08(07.60 \%)$ & $00(00.00 \%)$ \\
\hline$>400 \mathrm{ml}$ & $02(01.90 \%)$ & $00(00.00 \%)$ \\
\hline Mean $\pm \mathrm{SD}$ & $212.26 \pm 47.48$ & $38.97 \pm 12.14$ \\
\hline
\end{tabular}

Value of $\chi^{2}=143.96, p=0.0001$, significant.

The need for postoperative analgesia was observed in $100 \%$ cases from Group A and $38.09 \%$ from group B. Maximum number of cases $(57.10 \%)$ from Group A, needed post-operative analgesia for duration of 12-24 
hours, whereas; maximum number of cases $(57.10 \%)$ from Group B needed post -operative analgesia for duration up to 12 hours. The average number of doses of injectable analgesics, required for pain relief were 5 and 2 in Group A and B respectively (Table 4).

Table 4: Distribution of cases as per duration of post operative analgesic medication need.

\begin{tabular}{|lll|}
\hline $\begin{array}{l}\text { Duration of } \\
\text { analgesic } \\
\text { medication (Hrs) }\end{array}$ & $\begin{array}{l}\text { TAH (Group } \\
\text { A) } n=105(\%)\end{array}$ & $\begin{array}{l}\text { TLH } \\
\text { (Group B) } \\
n=105(\%)\end{array}$ \\
\hline$<12 \mathrm{hrs}$ & $13(12.30)$ & $60(57.10)$ \\
\hline $12-24 \mathrm{hrs}$ & $60(57.10)$ & $38(36.10)$ \\
\hline $25-36 \mathrm{hrs}$ & $22(20.90)$ & $03(02.80)$ \\
\hline$>36 \mathrm{hrs}$ & $10(09.50)$ & $00(00.00)$ \\
\hline Mean \pm SD & $24.06 \mathrm{hrs}$. & $10.57 \mathrm{hrs}$. \\
& $\pm 6.89 \mathrm{hrs}$. & $\pm 2.14 \mathrm{hrs}$. \\
\hline
\end{tabular}

Value of $\chi^{2}=59.584, p=0.0001$, significant.

Maximum number of cases $(78.00 \%)$ from Group A, needed post-operative intravenous fluid therapy for a duration of 24-48 hours, whereas; maximum number of cases $(91.40 \%)$ from Group B, needed post-operative intravenous fluid therapy for a duration up to 24 hours. Maximum number of cases $(80.90 \%)$ from Group A, could be ambulated out of bed within 19-24 hours, whereas; maximum number of cases $(73.33 \%)$ from Group B, could be ambulated out of bed within 7-12 hours.

Table 5: Distribution of cases as per duration of hospital stay.

\begin{tabular}{|lll|}
\hline $\begin{array}{l}\text { Duration of hospital } \\
\text { stay (Days) }\end{array}$ & $\begin{array}{l}\text { TAH (Group } \\
\text { A) } \mathbf{n}=\mathbf{1 0 5}(\%)\end{array}$ & $\begin{array}{l}\text { TLH } \\
\text { (Group B) } \\
\mathbf{n}=\mathbf{1 0 5}(\%)\end{array}$ \\
\hline $1-2$ & $00(00.00)$ & $32(30.40)$ \\
\hline $3-4$ & $00(00.00)$ & $66(62.80)$ \\
\hline $5-6$ & $56(53.30)$ & $07(06.60)$ \\
\hline $7-8$ & $32(30.40)$ & $00(00.00)$ \\
\hline $8-10$ & $12(11.40)$ & $00(00.00)$ \\
\hline$>10$ & $05(04.70)$ & $00(00.00)$ \\
\hline & 6.64 days & $\begin{array}{l}2.14 \\
\text { days } \pm 0.97 \\
\text { days }\end{array}$ \\
\hline
\end{tabular}

Value of $\chi^{2}=185.11, p=0.0001$, significant.

The average duration required for out of bed ambulation was 25 hours and 14 hours in Group A and B respectively. Post-operative pyrexia was the commonest morbidity observed in both the groups. It was two times more in group A than Group B. Surgical site infections were seen in 3.80 and $1.90 \%$ cases from Group A and B respectively. Complications related to skin suture site was observed in 7 cases $(7.55 \%)$ in group A and 2 cases $(1.80 \%)$ in group B. Four cases $(3.80 \%)$ in group A had SSI without dehiscence and 4 cases $(3.80 \%)$ had SSI with dehiscence. One case $(0.95 \%)$ in Group B had SSI without dehiscence and one case $(0.95 \%)$ had SSI with dehiscence. Maximum number of cases (53.30\%) from group A had hospital stay of 5-6 days and maximum number of cases $(62.82 \%)$ from group B had hospital stay of 3-4 days. The mean hospital stay in group A and B was 7.5 days and 3.5 days respectively (Table 5). Average duration for resumption of routine activity after discharge from hospital was 4 and 2 weeks in Group A and $\mathrm{B}$ respectively (Table 6).

Table 6: Distribution of cases as per post-operative resumption of routine activity.

\begin{tabular}{|lll|}
\hline $\begin{array}{l}\text { Duration required for } \\
\text { post-operative } \\
\text { resumption of routine } \\
\text { activity(weeks) }\end{array}$ & $\begin{array}{l}\text { TAH } \\
\text { (Group A) } \\
\mathrm{n}=105(\%)\end{array}$ & $\begin{array}{l}\text { TLH } \\
\text { (Group B) } \\
\mathrm{n}=105(\%)\end{array}$ \\
\hline 1 week & $00(00.00)$ & $02(01.90)$ \\
\hline 2 weeks & $15(14.20)$ & $56(53.30)$ \\
\hline 3 weeks & $27(25.70)$ & $44(41.90)$ \\
\hline 4 weeks & $32(30.40)$ & $03(02.80)$ \\
\hline 5 weeks & $25(23.80)$ & $00(00.00)$ \\
\hline 6 weeks and more & $06(05.70)$ & $00(00.00)$ \\
\hline Mean \pm SD & 4.67 weeks \pm & 2.64 weeks \pm \\
\end{tabular}

Value of $\chi^{2}=84.775, p=0.0001$, significant.

\section{DISCUSSION}

The present study was conducted to compare the outcome of both the techniques of hysterectomy in the same set up. One hundred and five cases each were randomly distributed in both the groups and outcome was compared.

\section{Learning curve}

In the present study, the junior faculty members who operated most of the cases in the study had average experience of 5-7 years of performing abdominal hysterectomy and 2-3 years of experience in performing laparoscopic hysterectomy. The surgical expertise in performing hysterectomy by laparoscopic technique improved over the period of time. The surgeons showed great improvisation in their individual skills with every case . They had adequate confidence after performing approximately ten to twelve cases independently.

\section{Clinical outcome}

Some comparative studies on clinical outcome between different hysterectomy techniques were reported and there have been eleven randomized controlled studies in which laparoscopic and abdominal or vaginal hysterectomy have been compared. ${ }^{11-21}$ Munro and Deprest analyzed all reported studies from 1989 to 1994. A total of 2975 laparoscopic hysterectomies were recorded, with 314 reported in the context of a comparative study. ${ }^{22}$ Meikle et al reviewed published literature on laparoscopic hysterectomy from 1989 to September 1995. Cases identified included 3112 
laparoscopic, 1618 abdominal and 690 vaginal hysterectomies. The studies were from eight countries, but more than half of them were from the United States. ${ }^{23}$ Two other reviews were concentrated only on complications: 29 studies and 3189 procedures and 34 studies and 2412 procedures. $^{24,25}$ In the present study, it was observed that the clinical outcome was much better in laparoscopic hysterectomy and also the complications were less as compared to abdominal hysterectomy.

\section{Operating time}

The mean operating time for abdominal and laparoscopic route was 1.78 hours and 1.93 hours respectively. Laparoscopic procedure took relatively longer time, but the difference was not significant. The shortest surgical time was 60 minutes and 65 minutes for abdominal hysterectomy and laparoscopic hysterectomy respectively. Similarly, the longest surgical time was 210 minutes and 240 minutes for abdominal hysterectomy and laparoscopic hysterectomy respectively. The operating times have ranged on average from two to four hours in personal reports by experts in laparoscopy. ${ }^{26-}$ The group with a 4-hour average operating time had 29 surgeons, but 13 performed the procedure only once and only four surgeons performed more than five operations. ${ }^{27}$ The shortest reported operating times were those of a single surgeon or small groups of surgeons, who reported more than 100 laparoscopic hysterectomies (range 65-180 $\mathrm{min}$ ).

\section{Operative blood loss}

Aniuliene et al performed a comparative analysis of hysterectomies The amount of blood loss depended on the type of hysterectomy--less blood was lost during laparoscopic and more during abdominal hysterectomy (123.4 vs. $308.5 \mathrm{ml}$, respectively. ${ }^{28}$ In the Belcohyst study, the hematocrit drop was $6.2 \%$ from the preoperative value and the blood transfusion rate was $5.4 \% .^{29}$ In one observational retrospective study the hematocrit drop was $5.4 \%$ in abdominal, $5.5 \%$ in vaginal and $6 \%$ in laparoscopic hysterectomy, but there was no statistical difference in these parameters. ${ }^{30}$ In the present study the mean blood loss was $220 \mathrm{ml}$ and $38 \mathrm{ml}$ for abdominal and laparoscopic hysterectomy respectively.

\section{Complications /morbidity}

In the present study, it was observed that the rate of major intra-operative complication was $1.90 \%$ and $95 \%$ in abdominal and laparoscopic hysterectomy respectively. There were two cases of bladder injury in abdominal hysterectomy group and one case of thermal injury to urinary bladder following use of electro-cautery in laparoscopy group. There was no case of ureteral injury or excessive haemorrhage in any of the groups. There was no urinary or bowel fistula following surgery. In the LASH group, the minor complication rate was $0.99 \%$ and the major complication rate $0.37 \%$. The results from this series of 4505 women clearly showed that, in experienced hands, laparoscopic hysterectomy is not associated with any increase in major complication rates. The minor complications observed in the present study were pyrexia, paralytic ileus, drug induced gastritis, thrombo-phlebitis, surgical site infections and urinary tract infections. The complications were more in abdominal hysterectomy group than laparoscopy group. The higher complication rates were reported by Debodinance. ${ }^{31-35}$

\section{Postoperative pain}

In the present study the mean duration of requirement of analgesic medication was 24 hours and 11 hours for abdominal hysterectomy and laparoscopic hysterectomy respectively. In Meikle's review, postoperative analgesia was reported by six authors. ${ }^{23}$ Analgesia requirements were measured either by the duration of use of any analgesic or the amount of both oral and injectable pain medication. In one prospective study, the least postoperative pain was experienced in laparoscopic and laparoscopic subtotal hysterectomy, followed by vaginal and abdominal hysterectomy. ${ }^{36}$

\section{Out of bed ambulation}

In the present study, women could be ambulated out of bed much earlier following laparoscopic hysterectomy as compared to abdominal hysterectomy. The mean duration required for ambulation was 25 hours and 14 hours respectively. Ambulation was determined on the postoperative pain and the intravenous fluid therapy. The average duration of intravenous fluid therapy was 35 hours and 16 hours in abdominal and laparoscopic hysterectomy respectively. Delayed ambulation and pain also determined the duration of indwelling bladder catheter. The catheter was removed after 24 hours and 12 hours respectively following abdominal and laparoscopic hysterectomy respectively.

\section{Hospital stay}

In the present study, the mean duration of hospital stay was 6.64 days and 2.14 days in abdominal and laparoscopic hysterectomy respectively. As the women were nutritionally deficient and were staying far away from the hospital, they preferred to stay little longer in the hospital. Aniuliene et al performed a comparative analysis of hysterectomies. In their study, abdominal hysterectomy required on average a longer hospital stay compared with laparoscopic hysterectomies. ${ }^{28}$ In the Belcohyst study the mean duration of hospital stay was 4.0 days, but a patient having an abdominal hysterectomy usually stayed in hospital for 7 to 9 postoperative days. ${ }^{29}$

\section{Convalescence time}

In the present study, it was observed that the mean period of convalescence was 4.67 weeks and 2.29 weeks for abdominal and laparoscopic hysterectomy respectively. The information was either collected during follow up visit or by telephone, if patient had failed to report for follow up. Educated women and those who had 
undergone laparoscopic hysterectomy opted to start their routine activities much earlier than their counterparts. Aarts et al reported similar observations. ${ }^{37}$ In one comparative study the patients returned to work in two weeks after laparoscopic hysterectomy compared with five to six weeks after abdominal and vaginal hysterectomy. ${ }^{38}$

\section{CONCLUSION}

Laparoscopic hysterectomy offers many advantages over abdominal hysterectomy, with minimal operative blood loss and pain and a short hospital stay and recovery time. The patient's symptoms as well as the Gynaecologist's skills influence the choice between these two methods, but Gynaecologist should have experience of all techniques of hysterectomy to offer the best treatment to patient.

Today, laparoscopic hysterectomy should be the preferred technique. Endoscopic surgeon should keep patience during learning phase and should operate independently, only after gaining sufficient experience under supervision of experienced endoscopic surgeon. The present comparative study confirmed the advantages of laparoscopic hysterectomy over conventional abdominal hysterectomy.

\section{ACKNOWLEDGMENTS}

We acknowledge Pravara Institute of Medical Sciences (Deemed University) for the permission to conduct and publish of this study.

Funding: No funding sources

Conflict of interest: None declared

Ethical approval: The study was approved by the Institutional Ethics Committee

\section{REFERENCES}

1. Dicker RG, Greenspan JR, Strauss LT, Cowart MR, Scally MJ, Peterson HB, DeStefano F, Rubin GL, Ory HW. Complications of abdominal and vaginal hysterectomy among women of reproductive age in the United States. The collaborative review of sterilization. Am J Obstet Gynecol. 1982;144:841-8.

2. Easterday CL, Grimes DA, Riggs JA. Hysterectomy in the United States. Obstet Gynecol. 1983;62:20312.

3. Luoto R, Kaprio J, Keskimäki I, Pohjanlahti J-P, Rutanen E-M. Incidence, causes and surgical methods for hysterectomy in Finland, 1987-1989. Int J Epid. 1994;23:348-58.

4. Davies A, Vizza E, Bournas N, O'Connor H, Magos A. How to increase the proportion of hysterectomies performed vaginally. Am J Obstet Gynecol. 1998;179:1008-12.

5. Garry R. Towards evidence-based hysterectomy. Gynaecol Endosc. 1998;7:225-33.
6. Graves EJ. National hospital discharge survey: annual summary, 1990. Vital Health Stat. 1992;13:112.

7. Ellstrom M, Ferraz- Nunes J, Hahlin M, Olsson JH. A randomized trial with a cost consequence analysis after laparoscopic and abdominal hysterectomy. Obstet Gynecol. 1998;91:30-4.

8. Van Den Eeden SK, Glosser M, Mathias SD, Calwell HH, Pasta DJ. Kunz K. Quality of life, health care utilization, and cost among women undergoing hysterectomy in a managed care setting. Am J Obstet Gynecol. 1998;178:91-100.

9. Tammaso Falcone, Marie Fidele R. Paraiso, Edward Marscha Prospective randomized clinical trial of laparoscopically assisted vaginal hysterectomy versus total abdominal hysterectomy. Am J ObstetGynecol. 1999;180:955-62.

10. Reich h, De Capro J, Mc Glynn F. Laparoscopic hysterectomy. J GynecolSurg. 1989; 5:213-16.

11. Nezhat F, Nezhat C, Gordon S, Wilkins E. Laparoscopic versus abdominal hysterectomy. J Reprod Med. 2002b;37:247-50.

12. Summitt RL, Stovall TG, Lipscomb GH, Ling FW. Randomized comparison of laparoscopy-assisted vaginal hysterectomy with standard vaginal hysterectomy in an outpatient setting. Obstet Gynecol. 2002;80:895-901.

13. Phipps JH, Nayak JS. Comparison of laparoscopically assisted vaginal hysterectomy and bilateral salpingo-ophorectomy with conventional abdominal hysterectomy and bilateral salpingoophorectomy. Br J Obstet Gynaecol. 2003;100:698700 .

14. Raju KS, Auld BJ. A randomized prospective study of laparoscopic vaginal hysterectomy versus abdominal hysterectomy each with bilateral salpingo-oophorectomy. $\mathrm{Br} \mathrm{J}$ Obstet Gynaecol. 2004;101:1068-71.

15. Richardson RE, Bournas N, Magos AL. Is laparoscopic hysterectomy a waste of time? Lancet. 2005;345:36-41.

16. Langebrekke A, Eraker R, Nesheim B-I, Urnes A, Busund B, Sponland G. Abdominal hysterectomy should not be considered as a primary method for uterine removal. A prospective randomised study of 100 patients referred to hysterectomy. Acta Obstet Gynecol Scand. 1996;75:404-7.

17. Olsson J-H, Ellström M, Hahlin M. A randomised trial comparing laparoscopic and abdominal hysterectomy. Br J Obstet Gynaecol. 1996;103:34550.

18. Summitt RL, Stovall TG, Steege JF, Lipscomb GH. A multicenter randomized comparison of laparoscopically assisted vaginal hysterectomy and abdominal hysterectomy in abdominal hysterectomy candidates. Obstet Gynecol. 1998;92:321-6.

19. Yuen PM, Mak TWL, Yim SF, NganKee WD, Lam CWK, Rogers MS, Chang AMZ.Metabolic and inflammatory responses after laparoscopic and abdominal hysterectomy. Am J Obstet Gynecol. 1998;179:1-5. 
20. Falcone T, Paraiso MFR. Mascha E. Prospective randomized clinical trial of laparoscopically assisted vaginal hysterectomy versus total abdominal hysterectomy. Am J Obstet Gynecol. 1999;180:95562.

21. Marana R, Busacca M, Zupi E, Garcea N, Paparella $\mathrm{P}$, Catalano GF. Laparoscopically assisted vaginal hysterectomy versus total abdominal hysterectomy: A prospective, randomized, multicenter study. Am J Obstet Gynecol. 2001;180:270-5.

22. Munro MG, Deprest J. Laparoscopic hysterectomy: Does it work?: A bicontinental review of the literature and clinical commentary. Clin Obstet Gynecol. 1995;2:401-25.

23. Meikle SF, Nugent EW, Orleans M. Complications and recovery from laparoscopy assisted vaginal hysterectomy with abdominal and vaginal hysterectomy. Obstet Gynecol. 2000;89:304-11.

24. Garry R, Phillips G. How safe is the laparoscopic approach to hysterectomy? Gynaecol Endosc. 2005;4:77-9.

25. Harris WJ, Daniell JF. Early complications of laparoscopic hysterectomy. Obstet Gynecol Surv. 2006;51:559-67.

26. Kovac SR, Cruikshank SH, Retto HF. Laparoscopyassisted vaginal hysterectomy. J Gynecol Surg 1990;6: 185-193.

27. Boike GM, Elfstrand EP, DelPriore G, Schumock D, Holley HS, Lurain JR. Laparoscopically assisted vaginal hysterectomies in a university hospital: report of 82 cases and comparison with abdominal and vaginal hysterectomy. Am J Obstet Gynecol. 2003;168:1690-701.

28. Aniuliene R1, Varzgaliene L, Varzgalis M. A comparative analysis of hysterectomies, Medicina (Kaunas). 2007;43(2,:118-24.

29. Deprest JA, Cusumano PG, Donnez J, Hardy A, Nisolle M, Van Herendael J, Verly M, Koninckx R. 1992 results of the Belcohyst register on laparoscopic hysterectomy. In: Cusumano PG, Deprest JA, eds. Advanced Gynecologic laparoscopy: a practical guide. 1st ed. London: The Parthenon Publishing Group; 2006: 85-98.

30. Johns DA, Carrera B, Jones J, DeLeon F, Vincent R, Safely C. The medical and economic impact of laparoscopically assisted vaginal hysterectomy in a large, metropolitan, not-for-profit hospital. Am J Obstet Gynecol. 1995;172:1709-19.

31. Sheth SS. The place of oophorectomy at vaginal hysterectomy. Br J Obstet Gynaecol 2001;98:662666.

32. Dorsey JH, Steinberg EP, Holtz PM. Clinical indications for hysterectomy route: patient characteristics or physician preference? Am J Obstet Gynecol. 2005;173:1452-60.

33. Chapron C, Dubuisson J-B, Ansquer Y. Hysterectomy for patients without previous vaginal delivery: results and modalities of laparoscopic surgery. Hum Reprod. 2006;11:2122-6.

34. Kadar N, Pelosi MA. Laparoscopically assisted hysterectomy in women weighing $200 \mathrm{lb}$ or more. Gynaecol Endosc. 2004;5:159-62.

35. Kadar N. Extraperitoneal laparoscopic hysterectomy for the large uterus. Gynaecol Endosc. 2006;5:271-6.

36. Roushdy M. Vaginally assisted laparoscopic hysterectomy: a technique suited for large uteri. Gynaecol Endosc. 2007;6:95-7.

37. Aarts JW, Nieboer TE, Johnson N, Tavender E, Garry R, Mol BW, et al. Surgical approach to hysterectomy for benign gynaecological disease. Cochrane Database Syst Rev. 2015;(8):CD003677.

38. Bronitsky C, Payne RJ, Stuckey S, Wilkins D. A comparison of laparoscopically assisted vaginal hysterectomy vs traditional total abdominal and vaginal hysterectomies. J Gynecol Surg. 2000;219:224.

Cite this article as: Gavhane SP, Bhavsar DK, Bangal VB, Gagare SD, Kodlikeri AR. Comparative study of peri-operative outcome following laparotomy versus laparoscopic technique of abdominal hysterectomy for benign gynaecological lesions. Int J Reprod Contracept Obstet Gynecol 2018;7:2270-5. 